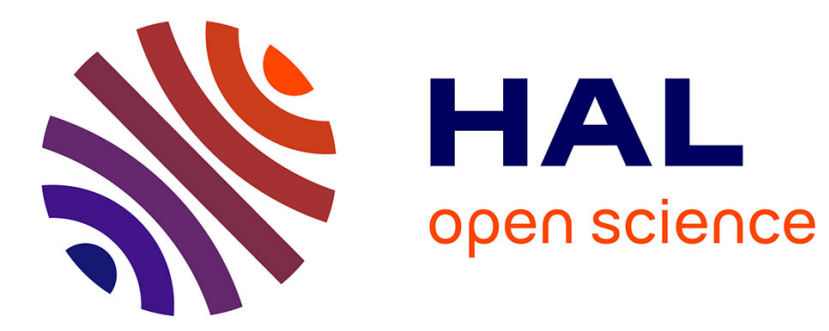

\title{
Ubiquitous presence of intermolecular CH...O hydrogen bonds in as-synthesized host-guest zeolite materials
}

\author{
Shadi Al-nahari, Karima Ata, Tzonka Mineva, Bruno Alonso
}

\section{To cite this version:}

Shadi Al-nahari, Karima Ata, Tzonka Mineva, Bruno Alonso. Ubiquitous presence of intermolecular CH...O hydrogen bonds in as-synthesized host-guest zeolite materials. ChemistrySelect, 2021, 6 (37), pp.9728-9734. 10.1002/slct.202102771 . hal-03364040

\author{
HAL Id: hal-03364040 \\ https://hal.science/hal-03364040
}

Submitted on 4 Oct 2021

HAL is a multi-disciplinary open access archive for the deposit and dissemination of scientific research documents, whether they are published or not. The documents may come from teaching and research institutions in France or abroad, or from public or private research centers.
L'archive ouverte pluridisciplinaire HAL, est destinée au dépôt et à la diffusion de documents scientifiques de niveau recherche, publiés ou non, émanant des établissements d'enseignement et de recherche français ou étrangers, des laboratoires publics ou privés. 


\section{Ubiquitous presence of intermolecular $\mathrm{CH}$...O hydrogen bonds in as-synthesized host-guest zeolite materials}

Shadi Al-Nahari, Karima Ata, Tzonka Mineva* and Bruno Alonso*

ICGM, Univ. Montpellier, CNRS, ENSCM, Montpellier, France.

\section{ABSTRACT}

$\mathrm{CH}$...O hydrogen bonds (HBs) are ubiquituous in silica zeolite crystals hosting cationic Organic Structure Directing agents (OSDAs). This new finding is notably supported by a correlation between experimental C-O distances and COSi angles' distributions of two series of 19 and 11 available structures. The correlation enables to asses the directionality of the $\mathrm{CH}$...O intermolecular interactions and to extrapolate a geometrical model for the hydrogen bonded moeities. DFT-D3 calculations on representative structures further confirmed the presence of these $\mathrm{HBs}$ and their geometry on the basis of $\mathrm{H}-\mathrm{O}$ distances, $\mathrm{CHO}$ angles and electron density. The reported insights demonstrate also the particularities of these intermolecular interactions in terms of charge distribution and electrostatic potentials. Further, multiple hydrogen bonding is evidenced between OSDAs and zeolites' channels and cages, opening new perspectives in the study of zeolite-OSDA host-guest interactions.

\section{KEYWORDS}

Crystal structures - Density functional calculations - Hydrogen bonds - Noncovalent interactions - Zeolites 


\section{INTRODUCTION}

Weak hydrogen bonds (HBs) involving $\mathrm{CH}$ bonds as donor groups and $\mathrm{O}$ as acceptor atoms have been evidenced decades ago for crystalline organic molecules. ${ }^{[1-3]}$ Since then, they have a recognized role in biology and in several areas of chemistry ${ }^{[4]}$ thanks to their implications in molecular properties like crystal packing, ${ }^{[8,}$

9] supramolecular assembly's formation, ${ }^{[10]}$ conformational states, ${ }^{[8,11,12]}$ host-guest interactions and molecular recognition, ${ }^{[13,14]}$ organic-inorganic hybrid networks ${ }^{[15]}$ and drug discovery ${ }^{[16]}$ to name a few.

In zeolite chemistry, $\mathrm{CH}$... O HBs have been scarcely investigated although they are one of the possible intermolecular interactions between cationic organic structure directing agents (OSDAs) and silica frameworks (FWs), and might therefore participate to zeolite formation and structure direction. The formation of intermolecular $\mathrm{CH}$... O HBs has been demonstrated in some as-synthesized clathrates or zeolites using positively charged metal complexes as OSDAs. ${ }^{[17,18]}$ These interactions have also been observed occasionally when using more standard cationic OSDAs like imidazoliums or tetraalkylammoniums. ${ }^{[19,20]}$ In some particular cases, the identified $\mathrm{CH}$...O HBs are of intramolecular nature for cationic OSDAs like choline bearing both tetralkylammonium and hydroxide functions. ${ }^{[21,22]}$ Besides, studies on the mechanisms of $\mathrm{CH}$ activation of alkanes adsorbed in acidic zeolites have highlighted the role of these weak HBs. ${ }^{[23,24]}$ It appears therefore that $\mathrm{CH}$... O hydrogen bonding can form in zeolites and might play an important role for organisation of the zeolite framework around OSDAs, but this but remains largely neglected until now when considering OSDA-zeolite intermolecular interactions.

Using variable temperature IR spectroscopy and ab initio dynamics simulation, we have recently investigated the presence and characteristics of $\mathrm{CH}$... $\mathrm{O} \mathrm{HBs}$ in silicalite-1 (MFI) containing tetrapropylammonium cations and fluorine atoms. ${ }^{[25]}$ This study allowed to evidence 28 weak $\mathrm{CH} . . . \mathrm{O}$ HBs that represent $30 \%$ of the energy of the Coulomb electrostatic interaction between OSDA and the MFI zeolite framework, demonstrating the importance of such HBs in terms of number and intensity. From these preliminary works, we were inclined to think that the presence of $\mathrm{CH}$... O HBs can be a general property of as-synthesised zeolites as there is no reason a priori that these interactions are not playing a role in similar chemical systems. This is what we found of interest to verify by studying the widest possible series of OSDA-zeolite structures, and an appropriate selection of DFT optimised model structures.

\section{RESULTS AND DISCUSSION}

\section{Crystal strutures' analysis}

Inspection of the available structures in crystallographic databases revealed a limited number of sets of chemically similar OSDA-zeolite structures. Among them, we chose to investigate first a full series found for 
19 pure and non-defective silica structures presenting defined positions for $F$ atoms (fluoride route) and nonprotonated ammonium organocations $\mathrm{C}_{x} \mathrm{H}_{\mathrm{y}} \mathrm{N}_{z}{ }^{\mathrm{nt}}$ with different charge density as OSDAs (Table S1). This choice allows to focus on the presence of $\mathrm{CH}$...O interactions for a series presenting the wanted diversity in $\mathrm{FW}$ and OSDA types, avoiding side questions about the presence of strong $\mathrm{HBs}$ (e.g. NH...O) or the uncertainties on the location of negative charges (e.g. using hydroxide routes). Moreover, the conclusions drawn here from this first series can be extended to a series of structures of different composition (vide infra).

As hydrogen atoms are not, or not precisely, located in most of the available crystal structures, we exploited $\mathrm{C}, \mathrm{O}$ and $\mathrm{Si}$ atomic positions. Indeed, distances between $\mathrm{C}$ and $\mathrm{O}$ atoms $d_{C O}$ can give a strong indication about the presence of $\mathrm{CH}$...O HBs. From Desiraju and Steiner work, ${ }^{[5]} d_{c o} \leq 3.3 \AA$ demonstrates the formation of these HBs, but longer distances (up to $4.0 \AA$ ) can also be considered for $\mathrm{CH}$...O HBs. The analysis of the 19 silica- $-\mathrm{C}_{\mathrm{x}} \mathrm{H}_{\mathrm{y}} \mathrm{N}_{z}{ }^{\mathrm{n}+}$ zeolites allows to extract 19 individual distributions in $d_{C O}$ and $d_{C S i}$ (C-Si distances) further combined into two distributions presented in Figure 1. These average distributions form almost continuous curves that are representative of the 19 individual distributions (Figure S2). A gradual increase in frequency counts is observed when increasing $d_{C O}$ and $d_{C S i}$ as well as a decrease when approaching the limit considered for the distributions ( $5 \AA$ ). We are therefore probing the first shell of $C$ atoms close to the silica FW. The first conclusion we can draw is the presence of a significant proportion of cases ( $35 \%$ ) for $d_{c o} \leq 4 \AA$, and a small but non-negligible proportion (4\%) for $d_{c o} \leq 3.3 \AA \AA$. It is to note that 15 structures over 19 present at least one CO moieties verifying $d_{C O} \leq 3.3 \AA$, and all of them present $d_{c O} \leq 3.5 \AA$. Herein, the existence of $\mathrm{CH}$...O HBs is demonstrated, although the alternative presence of H...O van der Waals (vdW) interactions cannot be ruled out at this stage for the cases where $d_{C O}>3.3 \AA$. The second conclusion is that the $d_{C S i}$ distribution start at higher values ( $3.6 \AA$ ) than the $d_{c o}$ distribution. It can be argued again that this is an effect of vdW interactions owing to the differences in vdW radii beween $\mathrm{O}$ and Si (1.52 and $2.10 \AA$ respectively ${ }^{[26]}$ ). Nevertheless, by inspecting each structure, we found always for a given $\mathrm{C}$ atom (considered in these distributions) an $\mathrm{O}$ atom that is closer to $C$ than to a Si atom. Therefore $d_{C O}<d_{C S i}$ is always obeyed, and there is no case showing a preferential proximity of $\mathrm{C}$ towards $\mathrm{Si}$. 


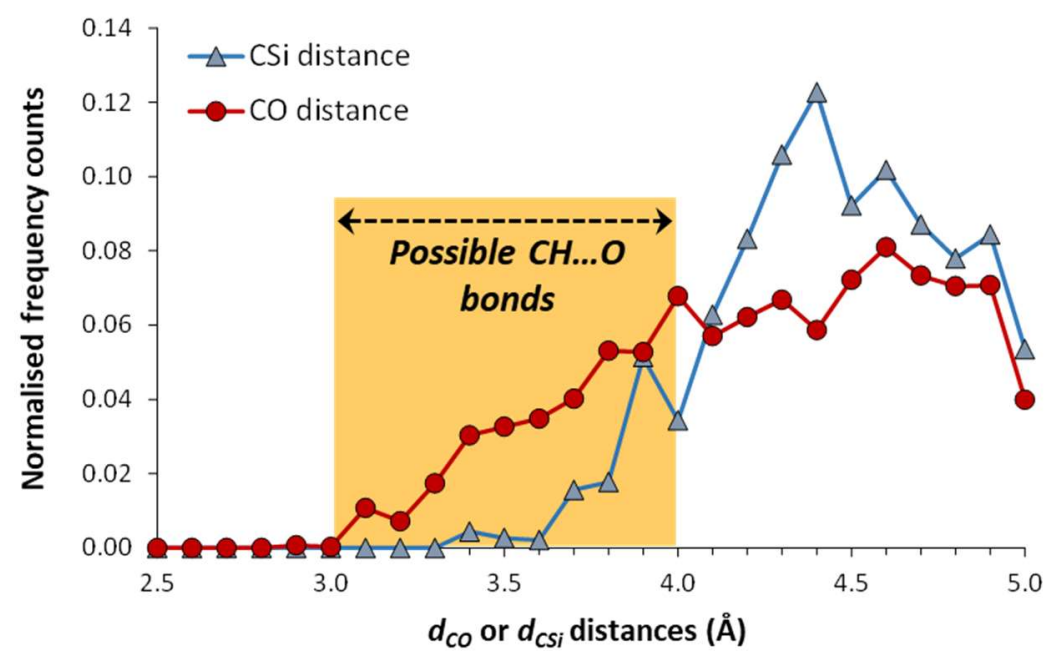

Figure 1. C-O and C-Si distance distributions for the series of 19 silica- $-\mathrm{C}_{x} \mathrm{H}_{\mathrm{y}} \mathrm{N}_{z}{ }^{\mathrm{n}+}$ zeolite structures.

One property of $\mathrm{HBs}$ is their directionality. ${ }^{[27]}$ In the case of weak HBs, this property allows to distinguish them from vdW interactions. ${ }^{[28]}$ For the experimental crystal structures, we addressed this question of directionality by analysing $d_{C O}$ as a function of the distribution in COSi angles, for the SiOSi siloxane bonds involving $\mathrm{O}$ (contour lines in Figure 2). This distribution is clearly not random for the $d_{c o}$ range explored (2.5$5.0 \AA$ ) on the contrary to what is obtained at higher $d_{c o}$ values for which COSi angles take all possible values with a mean at $90^{\circ}$ (example in Figure S3). Herein the interactions involving $\mathrm{C}, \mathrm{H}$ and $\mathrm{O}$ atoms have a directional character and can definitively be ascribed to HBs. In the contour map, a maximum in density is found for a COSi angle of $95^{\circ}$ and $d_{C O}=4.0 \AA$. But subtle variations can be noticed by analysing the angle distribution as a function of $d_{c o}$. For a given $d_{c o}$ interval, the COSi angle distribution follows a normal law (Gaussian fits in Figure 2). The width of these distributions decreases when $d_{c o}$ shortens while their centre deviates more from $90^{\circ}$. For the smallest $d_{c O}(3 \pm 0.25 \AA ̊)$ - related to the strongest $\mathrm{CH}$...O HBs - the highest probability is obtained for COSi angles of $104.4 \pm 0.2^{\circ}$. It is important to note that exactly the same conclusions on $d_{C O}, d_{C S i}$ and COSi angles distributions are deduced for a second series of 11 silica- $\mathrm{C}_{x} \mathrm{H}_{\mathrm{y}} \mathrm{O}_{\mathrm{w}} \mathrm{N}_{z}{ }^{\mathrm{n}+}$ crystal structures not containing $F$ and with a larger variety of OSDAs (Supporting Information S4). This confirms the widespread formation of $\mathrm{CH}$...O HBs in OSDA-zeolite assemblies, and shows that this formation does not depend on the chemical composition of the negatively charged FW. ${ }^{[29]}$ 


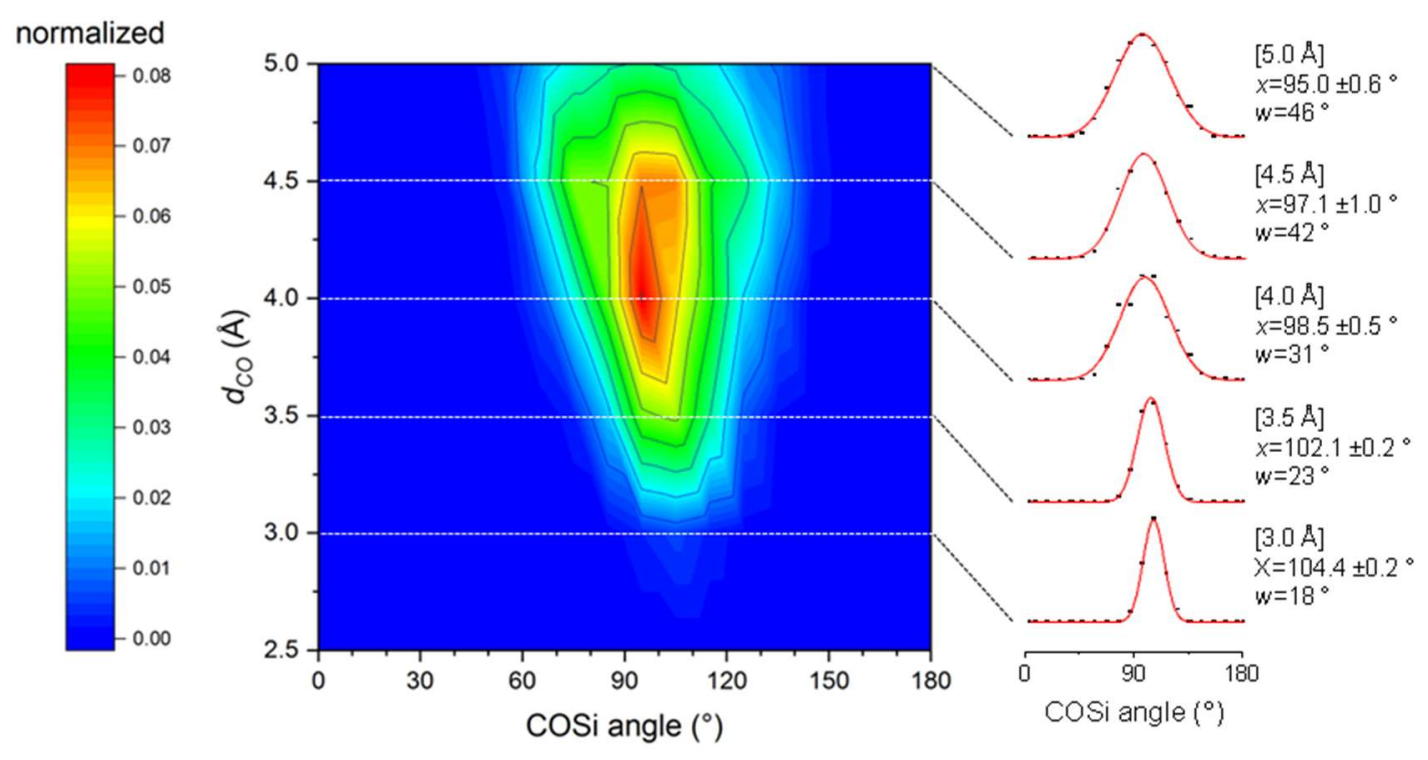

Figure 2. COSi angles and $d c o$ distributions for the series of 19 silica- $\mathrm{F}-\mathrm{C}_{\mathrm{x}} \mathrm{H}_{\mathrm{y}} \mathrm{N}_{\mathrm{z}}{ }^{\mathrm{n+}}$ zeolite structures presented as a density plot (frequency counts average over 5390 values). On the right, the graphs represent the angle distribution for a given $d_{c o}$ value $\pm 0.25 \AA$. The data are fitted with Gaussian functions (red curves) obtained by fitting. The centre and the width of the fitted distributions ( $x$ and $w$ respectively) are given.

Other insights are gained when analysing the relationship between the two COSi angles related to one C close to one SiOSi bond (Figure S5). The differences between these angles tend to decrease when $d_{c o}$ shortens. This means that $\mathrm{C}$ atoms become very close to the bisector plane of the SiOSi bonds when approaching $\mathrm{O}$ atoms. Concomitantly, the means of the two related COSi angles tend to a narrow range of values: $105-110^{\circ}$. These two observations from published crystal structures allow to build a model for the shortest CO distances. It is to note that the average bisector angle for SiOSi bonds in the series of 19 structures is $74^{\circ}$ $\left( \pm 5^{\circ}\right)$. Therefore, any $X$ atom coplanar with these bonds and belonging to the bisector plane would have a XOSi angle of $106^{\circ}$ in average, and this value is within the COSi values that can be extrapolated from the distributions in Figures $\mathbf{2}$ and $\mathbf{S} 5$ for $d_{C O}<3 \AA$, corresponding to the strongest $\mathrm{CH}$...O bond. This means that the related $\mathrm{C}$ atoms tend to locate within the SiOSi plane. Considering that the strongest $\mathrm{CH}$...O bonds might have $\mathrm{CHO}$ angles close to $180^{\circ}$, the resulting geometrical model for these bonds in zeolites that can be extrapolated from the angular measurements is presented in Scheme 1. Obviously, a strict coplanarity between all atoms has little chance to exist given the complex interplay of intra- and intermolecular interactions in the as-synthesized zeolites but this extrapolated model is not far to what is also observed in the DFT optimised structures (vide infra). 


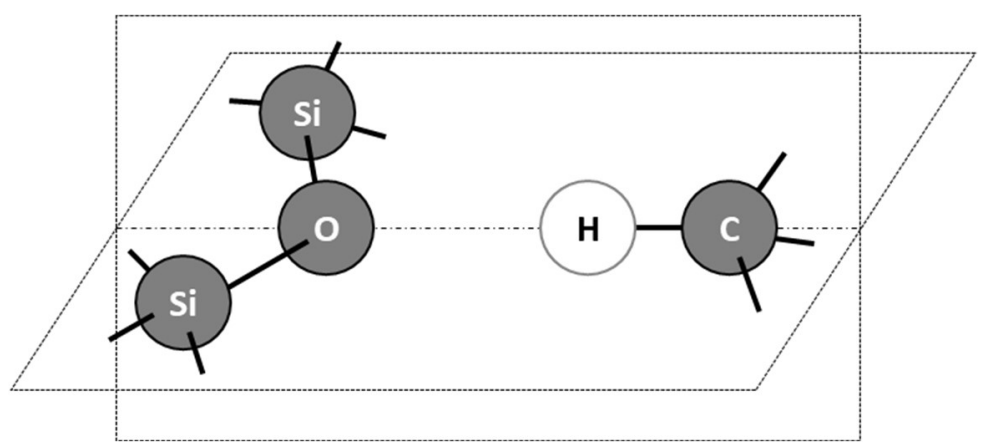

Scheme 1. Geometrical model for $\mathrm{C}, \mathrm{O}$ and $\mathrm{Si}$ atoms involved in $\mathrm{CH}$... O HBs extrapolated from COSi angle measurements on experimental crystal structures. $\mathrm{H}$ atom is placed here arbitrarily (see text).

\section{DFT study}

In order to complete the conclusions drawn for the study of the experimental crystal structures, we have optimised by DFT-D3 a series of five OSDA-silica structures selected from the first series of 19 structures (Table 1). This series is considered representative as it contains different FW types, pore channel dimensionality (from 0 to 3D) and F locations, and tetraalkylammonium or alkylimidizalium non-protonated cations $\mathrm{C}_{x} \mathrm{H}_{y} \mathrm{~N}_{z}{ }^{\mathrm{nt}}$ as OSDAs. In addition, it allows to explore a rather wide range of FW densities (Table 1), and interaction energies (Table S9). Last, one of the structures presents experimentally $d_{c o}>3.3 \AA$ (STT). The DFT calculations, incorporating a London dispersion term (D3 approach ${ }^{[30]}$ ), will allow the positioning of the $\mathrm{H}$ atoms and an analysis of the properties of $\mathrm{CH}$...O bonds. DFT functional and basis sets have been selected so as to yield the most realistic picture for the silica FW and the intermolecular interactions (Supporting Information S6).

Table 1. Characteristics of OSDA-silica structures selected for the DFT-D study.

\begin{tabular}{ccccc}
\hline FW type & $\begin{array}{c}\text { Pore channel } \\
\text { dimensionality }\end{array}$ & F location & OSDA $^{a}$ & $\begin{array}{c}\text { FW density } \\
\left(\mathrm{T} / 1000 \AA^{3}\right)^{b}\end{array}$ \\
\hline AST & O D & {$\left[4^{6}\right]$} & TMA & 15.8 \\
TON & 1 D & {$\left[6^{2} 5^{2}\right]$} & TMI & 18.1 \\
ITW & 2 D & {$\left[4^{6}\right]$} & TMI & 17.7 \\
STT & 2 D & {$\left[5^{4} 4^{3}\right]$} & TMAda & 17.0 \\
MFI & 3 D & {$\left[4^{1} 5^{2} 6^{2}\right]$} & TPA & 18.4
\end{tabular}

a. TMA (tetramethylammonium), TMI (1,3,4-trimethylimidazolium), TPA (tetrapropylammonium), TMAda (trimethyladamantanium). b. Values retrieved from the IZA structure database.

We have first verified that the trends found above for CO and CSi distances and COSi angles in already published structures remain valid for the optimised structures (Figure S7). The choice of the five OSDA-silica 
structures and their DFT modelling allow to model the experimental distance distributions (Figure S7A). Besides, the correlation pattern for $d_{C O}$ as a function of COSi angles is also reproduced for the DFT optimized structures (Figure S7B). Second, we observe for these latter models that there are always small H-O distances $\left(d_{H O}<2.7 \AA\right.$, below the sum of $\left.\mathrm{vdW} \mathrm{radii}^{[26]}\right)$ and that they are related to large $\mathrm{CHO}$ angles $\left(>90^{\circ}\right)$ (Figure 3). The shorter these distances are, the closer to $150-180^{\circ}$ the angles are. These are clear indications of the presence of weak but still directional $\mathrm{CH} . . . \mathrm{O} \mathrm{HBs}{ }^{[5,28]}$ When inspecting closely the geometry of the four shortest $\mathrm{CH}$... O bonds for each OSDA-zeolite assembly, we found $d_{H O}<2.6 \AA \AA$ and $\mathrm{CHO} \geq 126^{\circ}$ for all structures (Table S8). In addition, mean COSi angles are in the $100^{\circ}-112^{\circ}$ range containing the limit value of $106^{\circ}$ discussed above. Furthermore, $\mathrm{C}, \mathrm{O}$ and $\mathrm{Si}$ atoms are nearly coplanar. The atoms are out-of-plane at distances $<0.5 \AA$ (often < $0.2 \AA$ ), and SiSiOC dihedral angles are between 115 and $175^{\circ}$ (often $>140^{\circ}$ ), in global agreement with the extrapolated model obtained from crystal structures (Scheme 1). $\mathrm{H}$ atoms are close to be coplanar with $\mathrm{C}, \mathrm{H}, \mathrm{O}$ and $\mathrm{Si}$ atoms (out-of-plane distances $<0.6 \AA$ ). Further, we notice that the $\mathrm{O}$ atoms involved in these $\mathrm{HBs}$ are very often belonging to the silica cages containing $\mathrm{F}$ ( 8 over 20 ) or to the siloxane bonds directly attached to these cages (11 over 20). This evidences that charge distributions can play an important role in the formation of these weak HBs that are almost electrostatic in nature. ${ }^{[5,31]}$

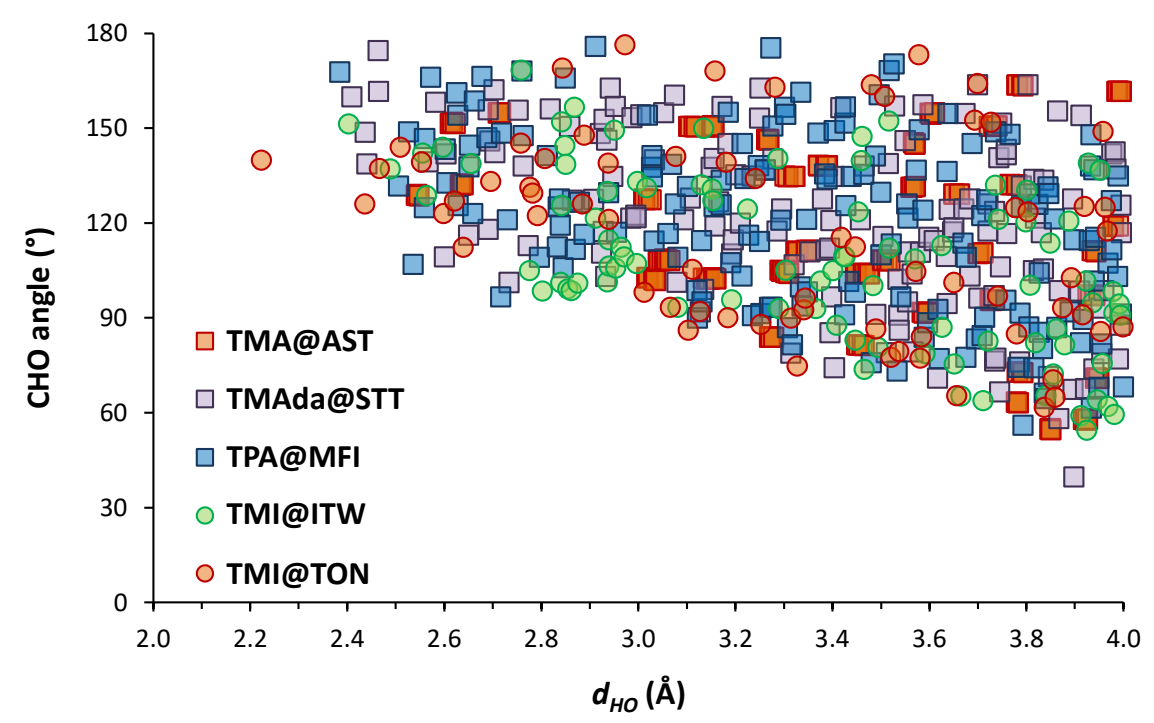

Figure 3. $\mathrm{CHO}$ angles in optimised zeolite structures as a function of $d_{H O}$ distances.

From Mulliken charge analysis (Table S9), the silica FWs including F have a total charge close to -1 , with F partial charges well above -1 (mean: $-0.57 \pm 0.05$ ). The latter slightly depend on the nature and strength of the $\mathrm{F}-\mathrm{Si}$ interactions, covalent (-0.52 to -0.56 for $\mathrm{F}$ in large cages) or tetrel bonding (-0.66 for $\left[4^{6}\right]$ cages). We notice also that $O$ atoms have always negative partial charges around -1 (mean: $-0.96 \pm 0.04$ ). In the case of the OSDAs, $\mathrm{N}$ atoms bear negative charges (ca. -0.8 for tetraalkylammoniums and -0.5 for TMI) while the charge of $\mathrm{C}$ depends on its proximity to $\mathrm{N}$. Significantly, all $\mathrm{H}$ - that are the peripheral atoms of the OSDAs are always slightly positively charged (mean: $+0.07 \pm 0.02$ ). Therefore, the difference between $\mathrm{H}$ and $\mathrm{O}$ partial 
charges is equal or higher than +1 . This high polarisation between the outer OSDAs' surfaces and $O$ atoms of the siloxane bonds strengthens the formation of $\mathrm{HBs}$ like in a charge-assisted process; ${ }^{[32]}$ a strengthening already observed for organocations like tetramethylammonium. ${ }^{[33]}$ It is also to note that the above distribution in partial charges is only valid for the OSDA-zeolite assembly. If the silica FW (with F) and the OSDA are considered separately (Table S9), the siloxane bonds are less polarised with higher O partial charges $(-0.62 \pm 0.03)$.

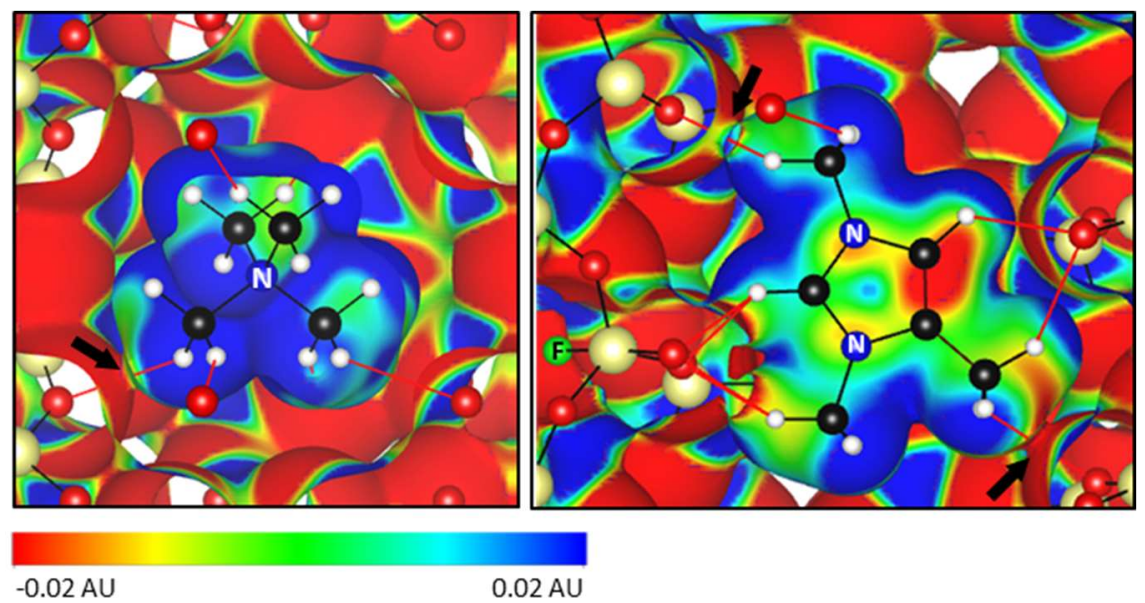

Figure 4. Electrostatic potentials mapped on the electron charge density iso-surfaces (isovalue at 0.047 e. $\AA^{-3}$ ) of TMA@AST and TMI@TON models. Surfaces have been cut so as to present the internal OSDA structure. Covalent bonds and $\mathrm{HBs}\left(d_{H O}<2.7 \AA\right)$ are represented as black and red lines. C, H, N, O, Si and F atoms are represented as balls using CPK convention (black, white, blue, red, yellow and green resp.)

We have calculated and plotted electron density maps coloured by the electrostatic potential (ESP) for the five modelled OSDA-zeolite assemblies (Figure S10). Figure 4 illustrates the typical hydrogen bonding schemes of tetraalkylammonium and imidazolium OSDAs, exemplified here by TMA@AST and TMI@TON assemblies. Several characteristics are noticeable. For the strongest HBs shown $\left(d_{H O}<2.7 \AA\right)$, the electron charge density, here at an isovalue of 0.047 e. $\AA^{-3}$, shows a continuity along H...O (e.g. black arrows in Figure 4). The electron density, above this isovalue, does not vanish between $\mathrm{H}$ and $\mathrm{O}$, which demonstrates its delocalization along the $\mathrm{CH}$...O bonds. This is in line with recent findings for a series of weak and strong $\mathrm{H}$ bonds in a variety of molecular structures. ${ }^{[34]}$ In addition, ESPs can be used to evaluate hydrogen bonding. ${ }^{[35,36]}$ We found here significant contrasts between ESPs of the OSDAs (more positive) and the FWs (more negative), showing the known complementarity between $\mathrm{H}$-donors and $\mathrm{H}$-acceptors in $\mathrm{HBs}{ }^{[35,37]}$ These contrasts exist at each side of the $\mathrm{CH}$... O HBs and cancel between $\mathrm{H}$ and $\mathrm{O}$. When the donor (OSDA) and acceptor groups $(\mathrm{O})$ are considered separately the differences in ESP are sharper, as appreciated for TMAda@STT in Figure S11. This observation can be related to the perturbing effect of HBs on the molecular electrostatic potentials. ${ }^{[37,38]}$ If we have now a more global look to Figure 4, we observe that mono- and bifurcated HBs are anchoring the OSDAs inside the cage (AST) or the pore channel (TON). Reciprocally the OSDAs can be seen as attracting the silica tetrahedra around them. 
These characteristics of $\mathrm{CH} . . . \mathrm{O} \mathrm{HBs}$ are valid for all modelled OSDA-zeolite assemblies. Figure 5 represents the $\mathrm{H}$-bonding scheme around OSDAs for the strongest $\mathrm{HBs}\left(d_{H O}<2.7 \AA ̊ \AA\right)$. Interestingly, these $\mathrm{HBs}$ are present in various directions and are connecting a high number of $\mathrm{O}$ atoms, equal or above the total number of $\mathrm{C}$ in OSDAs (from 6 to 15, Figure S12). For instance, in the case of a 3D pore channel like MFI, the four propyl arms of TPA are forming HBs with $\mathrm{O}$ atoms in straight or zig-zag channels. This multiple anchoring originates in the high difference in charges existing between all $\mathrm{O}$ and $\mathrm{H}$ atoms (vide supra). Meanwhile, other $\mathrm{HBs}$ can be formed when the OSDAs are subjected to dynamics. Using Born-Oppenheimer molecular dynamics simulations on a cluster model representative of the TPA@MFI assembly, we demonstrated recently this ability of the $\mathrm{CH}$... O HBs to be continuously formed and disrupted depending on the competition between thermally activated OSDA motions and attractive HBs interactions. ${ }^{[25]}$ The analysis of these dynamics lead then to distinguish between stable and instable (transitory) HBs. All these directional bonds coming from the outer surface of the OSDAs will collectively participate to the global stabilisation of the FW topology and to structure direction, along with the most usually considered Coulomb and vdW interactions. ${ }^{[39-41]}$

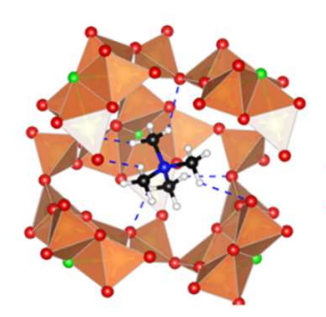

TMA@AST
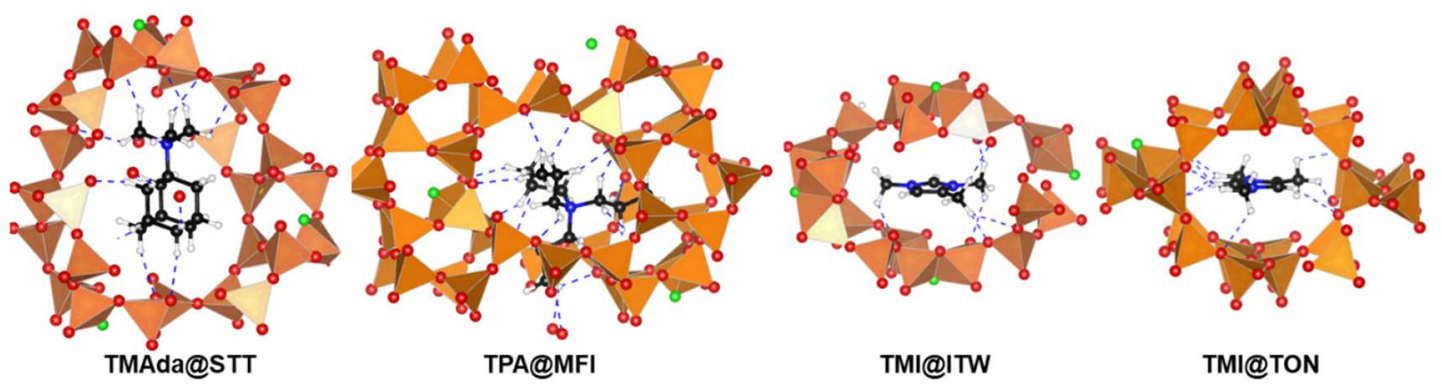

Figure 5. Visualisation of $\mathrm{CH}$...O HBs $\left(d_{H O}<2.7 \AA\right.$, dashed lines) for the modelled OSDA-zeolite assemblies. Si atoms are represented at the centre of the polyhedra. $\mathrm{C}, \mathrm{H}, \mathrm{N}, \mathrm{O}$ and $\mathrm{F}$ atoms are represented as balls using $\mathrm{CPK}$ convention (black, white, blue, red, green resp.).

\section{CONCLUSIONS}

We have therefore demonstrated that $\mathrm{CH}$...O hydrogen bonds between cationic OSDAs and silica FWs are ubiquitous for two series of 19+11 available experimental crystal structures presenting welldefined positions for $\mathrm{C}$ and $\mathrm{N}$ atoms of the OSDAs, and for $\mathrm{Si}$ and $\mathrm{O}$ atom of the FWs. A geometrical model for these HBs is extrapolated from the COSi and SiOSi angles measurements, showing a tendency to coplanarity for $\mathrm{C}, \mathrm{O}$ and $\mathrm{Si}$. The study of OSDA-zeolite assemblies using state-of-the-art DFT-D3 methods confirms these conclusions and shows the importance of the electrostatic interaction in the formation of these HBs. It appears in particular that the positive charges of cationic OSDAs are beard by all the peripheral $\mathrm{H}$ atoms. This favours the formation of multiple $\mathrm{CH}$...O bonds with the negatively charged $\mathrm{O}$ atoms of the zeolite framework. Albeit weak when considered 
individually, these multiple and directional bonds participate thus to the stabilisation of the OSDAzeolite assemblies, and have to be considered collectively when discussing the intermolecular interactions that drive zeolites' structure direction.

\section{ACKNOWLEDGEMENTS}

This work is supported by the CNRS, the French National Research Agency (project ZEOORG ANR-19CE29-0008-01), and the Algerian Bourses d'Excellence program. SA thanks EACEA for the Erasmus Mundus scholarship (program EM3E-4SW). KA and TM acknowledge the granted access by GENCI to the HPC resources of CCRT/CINES/IDRIS (allocation A0090807369).

\section{CONFLICT OF INTEREST}

The authors declare no conflict of interest. 


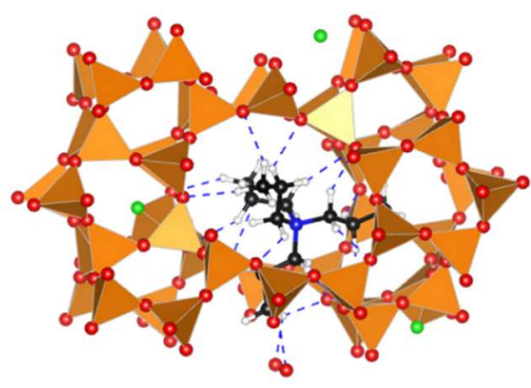

Multiple $\mathrm{CH}$... O hydrogen bonding between cationic organic structure directing agents and silica frameworks is found ubiquitous in as-synthesized zeolites, and has to be considered among the important intermolecular host-guest interactions involved in structure direction. 


\section{NOTES AND REFERENCES}

[1] D. J. Sutor Nature. 1962, 195, 68-69.

[2] D. J. Sutor J. Chem. Soc. . 1963, 1105-1110.

[3] R. Taylor, O. Kennard J. Am. Chem. Soc. 1982, 104, 5063-5070.

[4] G. R. Desiraju Acc. Chem. Res. 1996, 29, 441-449.

[5] G. R. Desiraju, T. Steiner, The Weak Hydrogen Bond: In Structural Chemistry and Biology, Oxford University Press Oxford, 2001.

[6] M. C. Wahl, M. Sundaralingam Trends Biochem. Sci. 1997, 22, 97-102.

[7] D. Braga, F. Grepioni, G. R. Desiraju Chem. Rev. 1998, 98, 1375-1406.

[8] T. Steiner Crystallog. Rev. 2003, 9, 177-228.

[9] R. Taylor Cryst. Growth Des. 2016, 16, 4165-4168.

[10] F. M. Raymo, M. D. Bartberger, K. N. Houk, J. Fraser-Stoddart J. Am. Chem. Soc. 2001, 123, 9264-9267.

[11] O. Takahashi, Y. Kohno, M. Nishio Chem. Rev. 2010, 110, 6049-6076.

[12] C. R. Jones, P. K. Baruah, A. L. Thompson, S. Scheiner, M. D. Smith J. Am. Chem. Soc. 2012, 134, 12064-12071.

[13] J. Caia, J. L. Sessler Chem. Soc. Rev. 2014, 43, 6198-6213.

[14] C. Watanabe, Y. Okiyama, S. Tanaka, K. Fukuzawa, T. Honma Chem. Sci. 2021, 12, 4722-4739.

[15] C.-H. Zeng, Z. Luo, J. Yao CrystEngComm 2017, 19, 613-617.

[16] Y. Itoh, Y. Nakashima, S. Tsukamoto, T. Kurohara, M. Suzuki, Y. Sakae, M. Oda, Y. Okamoto, T. Suzuki Sci. Rep. 2019, 9, 767.

[17] P. Behrens, G. van de Goor, C. C. Freyhardt Angew. Chem. Int. Ed. 1996, 34, 2680-2682.

[18] P. Behrens, C. Panz, V. Hufnagel, B. Lindlar, C. C. Freyhardt, G. van de Goor Solid state lonics. 1997, 101-103 229234.

[19] C. M. Zicovich-Wilson, F. Gandara, A. Monge, M. Camblor J. Am. Chem. Soc. 2010, 132, 3461-3471.

[20] E. Dib, M. Freire, V. Pralong, T. Mineva, B. Alonso Acta Cryst. C. 2017, 73, 202-207.

[21] M. B. Park, S. J. Cho, S. B. Hong J. Am. Chem. Soc. 2011, 133, 1917-1934.

[22] J. K. Lee, J. H. Lee, N. H. Ahn, K. H. Cho, S. B. Hong Chem. Sci. 2016, 7, 5805-5814.

[23] M. J. Truitt, S. S. Toporek, R. Rovira-Truitt, J. L. White J. Am. Chem. Soc. 2006, 128, 1847-1852

[24] L. S. Sremaniak, J. L. Whitten, M. J. Truitt, J. L. White J. Phys. Chem. B. 2006, 110, 20762-20764.

[25] T. Mineva, E. Dib, A. Gaje, H. Petitjean, J.-L. Bantignies, B. Alonso ChemPhysChem. 2020, 21, 149 -153.

[26] A. Bondi J. Phys. Chem. 1964, 68, 441-451.

[27] E. Arunan, G. R. Desiraju, R. A. Klein, J. Sadlej, S. Scheiner, I. Alkorta, D. C. Clary, R. H. Crabtree, J. J. Dannenberg, P. Hobza, H. G. Kjaergaard, A. C. Legon, B. Mennucci, D. J. Nesbitt Pure Appl. Chem. 2011, 83, 1637-1641.

[28] T. Steiner, G. R. Desiraju Chem. Commun. 1998, 891-892.

[29] For instance, evidence for $\mathrm{CH}$...O formation ( $d_{c o} \leq 3.3 \AA ̊$ ) was also obtained for the few silica-germania and AIPO zeolitic crystal structures found containing $\mathrm{N}$ based cationic OSDAs.

[30] S. Grimme, J. Antony, S. Ehrlich, H. Krieg J. Chem. Phys. 2010, 132, 154104.

[31] T. Steiner Angew. Chem. Int. Ed. 2002, 41, 48-76. 
[32] D. Braga, F. Grepioni Acc. Chem. Res. 2000, 33, 601-608.

[33] C. E. Cannizzaro, K. N. Houk J. Am. Chem. Soc. 2002, 124, 7163-7169.

[34] Z. Zhang, D. Li, W. Jiang, Z. Wang Adv. Phys. X. 2018, 3, 1428915.

[35] B. Galabov, P. Bobadova-Parvanova, S.llieva, V. Dimitrova J. Mol. Struct. 2003, 630, 101-112.

[36] J. M. Andrić, M. Z. Misini-Ignjatović, J. S. Murray, P. Politzer, S. D. Zarić ChemPhysChem. 2016, $2035-2042$.

[37] L. F. Pacios in Changes of Electron Properties in the Formation of Hydrogen Bonds, (Ed. S. J. Grabowski), Springer, Dordrecht, Netherlands, 2006, pp.109-148.

[38] M. D. Ryan in Effect of Hydrogen Bonding on Molecular Electrostatic Potential, (Ed. D. Smith), Am. Chem. Soc., Washington, DC, 1994, pp.36-59.

[39] H. Gies, B. Marker Zeolites. 1992, 12, 42-49.

[40] S. L. Burkett, M. E. Davis Chem. Mater. 1995, 7, 920-928.

[41] L. Gómez-Hortigüela, M. A. Camblor in Introduction to the Zeolite Structure-Directing Phenomenon by Organic Species: General Aspects., (Eds.: L. Gómez-Hortigüela, M. A. Camblor), Springer, Cham, 2017, pp.1-41.

[42] R. Dovesi, A. Erba, R. Orlando, C. M. Zicovich-Wilson, B. Civalleri, L. Maschio, M. Rérat, S. Casassa, J. Baima, S. Salustro, B. Kirtman WIREs Computational Molecular Science. 2018, 8, e1360.

[43] X. Yang Mater. Res. B. 2006, 41, 54-66.

[44] E. Aubert, F. Porcher, M. Souhassou, V. Petříček, C. Lecomte J. Phys. Chem. 2002, 106, 1110-1117.

[45] M. Camblor, M. Díaz-Cabañas, J. Perez-Pariente, S. J. Teat, W. Clegg, I. J. Shannon, P. Lightfoot, P. Wright, R. Morris Angew. Chem. Int. Ed. 1998, 37, 2122-2126.

[46] X. Yang, M. Camblor, Y. lee, H. Liu, D. Olson J. Am. Chem. Soc. 2004, 126, 10403-10409.

[47] M. F. Peintinger, D. V. Oliveira, T. Bredow J. Comput. Chem. 2013, 34, 451-459.

[48] K. Momma, F. Izumi J. Appl. Crystallogr. 2011, 44, 1272-1276.

[49] VMD in Visual Molecular Dynamics https://www.ks.uiuc.edu/Research/vmd/ . 